\title{
Minireview \\ Rheumatoid arthritis: GWAS or TMI?
}

\author{
Bruce N Cronstein
}

Address: New York University School of Medicine, 550 First Avenue, New York, NY 10016, USA. Email: cronsb01@med.nyu.edu

\begin{abstract}
Genome-wide association studies are the most comprehensive and straightforward approach to teasing out the identity of genetic polymorphisms associated with any given disease or characteristic. With the availability of DNA banks from large cohorts of ethnically matched patients and healthy individuals it is now possible to define even marginal genetic associations between genetic polymorphisms and diseases. As increasing numbers of these studies are carried out and as associations with smaller and smaller risks are identified, there is the growing concern that the findings will be of increasingly marginal value. Thus, the glut of new genetic associations is rapidly overwhelming our interest in the results, a situation that could be described as TMI (too much information). Recent genetic association studies in rheumatoid arthritis suggest that we may be approaching the TMI stage of genome-wide association studies.
\end{abstract}

\section{Introduction}

The risk of developing rheumatoid arthritis (RA), a common autoimmune disease characterized by inflammation and destruction of the joints, has long been known to be at least partially attributable to genetics. Recently, Gregersen and colleagues [1] reported that a common single nucleotide polymorphism (SNP) in the transcriptional regulatory gene $R E L$ confers a 1.2-fold greater risk of $\mathrm{RA}$, on the basis of a solid and extensive investigation of a genome-wide association study (GWAS) in a large cohort of patients. Increased risk of similar magnitude has also been associated with SNPs in several other genes. Clearly the genetic basis of RA is complex, and polymorphisms in various genes have been associated with a greater risk of developing RA or of greater severity of the disease once an individual has RA.

The techniques of GWAS can now be applied to a wider and wider range of diseases, thanks to technological advances in identifying genetic polymorphisms in large groups of individuals, advances in genotyping (for example, Gregersen et al. [1] included only RA patients expressing antibodies to citrullinated peptides), stronger collaborations among investigators at multiple institutions, and the availability of more sophisticated statistical and computational approaches to analyzing extremely large datasets. The studies described by Gregersen and colleagues [1] certainly exemplify a collaborative approach backed up by considerable technology and advanced data analysis. Investigators at 12 different academic institutions and one company in three different countries are listed as coauthors on the work, and state-of-the-art technology was used to analyze the frequency of 278,502 SNPs in 2,418 North American patients and 4,504 North American controls of European origin. The total number of patients was divided into discovery and replication cohorts to add rigor to the analysis, and the statistical analysis of the results was highly stringent and used standard computerized approaches. In addition to making the new observation on association of a SNP in REL with RA, the study also revealed associations with the genes encoding cytotoxic T-lymphocyte antigen 4 (CTLA4) and B-cell lymphocyte kinase (BLK) and confirmed the association of other genetic polymorphisms with RA, including the human leukocyte antigen (HLA) region [2], the protein tyrosine phosphatase gene PTPN22 [3] and the co-stimulatory protein gene $C D 4 O$ [4]. Interestingly, other than the HLA associations with RA, which are robust and have been observed in numerous studies, all of the associations observed here are modest, all in the range of a relative risk of 1.2.

\section{Low risk genotypes lead to better understanding}

The capacity to detect very small differences between disease and control populations and the reporting of such associations clearly demonstrates that the low-hanging fruit of genetic disease associations has been picked and we are now harvesting the fruit from the top of the tree. But is there similar nutritive value for these less accessible fruits? As the cost of sequencing an individual's entire genome falls and increasing numbers of individuals obtain this information about themselves, will modest disease associations, such as those observed by Gregersen et al. [1], clutter up an otherwise clear picture of genetic risk? Will these genetic associations illuminate new targets for therapy? It is unlikely that the information derived here will be useful in making a diagnosis of RA, but could this work lead to a better understanding of the disease?

$R E L$ is a member of the NFkB family of transcriptional regulators that have a prominent role in inflammation. On 
this basis alone, the findings described here confirm much of the biology previously worked out for RA. Although there is clear overlap in the functions of the members of this family of transcriptional regulators, $R E L$ seems to have an important role in the survival of activated $\mathrm{CD}^{+}$cells [5]. Thus, this work [1] might lead to a more nuanced understanding of the pathophysiology of RA that includes a more specific role for $\mathrm{CD}^{+} \mathrm{T}$ cells in the pathogenesis of RA.

In addition to the genetic contribution to the risk of developing RA, other environmental risk factors clearly have a role, and it is likely that environmental factors will also interact with the genetic factors predisposing to development of RA. It has long been known that living in an urban environment confers a greater risk of developing RA than living in a more rural environment [6-8]. Dietary factors have been implicated in some studies, although these findings are not very consistent [9,10]. Smoking is the single environmental factor that is most strongly and reproducibly linked with an increased risk of developing RA [9], although no interaction between smoking and known genetic risk factors has been observed [11,12].

\section{Where now for GWAS?}

As with so many technological advances, GWAS is now becoming 'routine' and is producing information about genetic risk factors that confer less and less risk. Nonetheless, the value of the technique is clear and the potential for contributing to a much more detailed and nuanced understanding of the genetic risk factors, the pathogenesis of the disease and the potential for defining new therapeutic targets is great. So, despite the identification of factors that confer less and less risk for the development of RA, the biological implications of the findings indicate that GWAS may produce important insights and not just too much information.

\section{Competing interests}

The author has patents on the use of adenosine A2A receptor agonists to promote wound healing, the use of adenosine A2A receptor antagonists for the treatment of fibrosis, the use of adenosine A1 receptor antagonists to treat osteoporosis and other bone diseases, the use of adenosine $\mathrm{A} 1$ and $\mathrm{A} 2 \mathrm{~B}$ receptor antagonists to treat fatty liver and the use of adenosine A2A receptor agonists to treat prosthesis loosening. During the past 2 years he has consulted for the following companies: Cephalon, Cypress Bioscience, Inc., King Pharmaceutical (licensee of patents above), CanFite Biopharmaceuticals, Bristol-Myers Squibb, Cellzome, Tap Pharmaceuticals, Prometheus Laboratories, Regeneron (Westat, DSMB), Sepracor, Amgen, Endocyte, Protalex, Allos, Inc., Combinatorx, Kyowa Hakka, HoffmanLaRoche, Savient, and Avidimer Therapeutics. He owns equity in CanFite Biopharmaceuticals and has received grants from the National Institutes of Health, King Pharmaceuticals and the Vilcek Foundation. He is on the board of directors of the Vilcek Foundation. He has received bagels, ice cream and other snacks from Eli Lilly \& Co, UCB, and Pfizer.

\section{Acknowledgements}

This work was supported by grants from the NIH (AR056672, AR054897 and UL1RR029893).

\section{References}

1. Gregersen PK, Amos CI, Lee AT, Lu Y, Remmers EF, Kastner DL, Seldin MF, Criswell LA, Plenge RM, Holers VM, Mikuls TR, Sokka T, Moreland LW, Bridges SL Jr, Xie G, Begovich AB, Siminovitch KA: REL, encoding a member of the NF-kappaB family of transcription factors, is a newly defined risk locus for rheumatoid arthritis. Nat Genet 2009, 41:820-823.

2. Gregersen PK, Silver J, Winchester RJ: The shared epitope hypothesis. An approach to understanding the molecular genetics of susceptibility to rheumatoid arthritis. Arthritis Rheum 1987, 30:1205-1213.

3. Lee AT, Li W, Liew A, Bombardier C, Weisman M, Massarotti EM, Kent J, Wolfe F, Begovich AB, Gregersen PK: The PTPN22 R620W polymorphism associates with RF positive rheumatoid arthritis in a dose-dependent manner but not with HLA-SE status. Genes Immun 2005, 6:129-133.

4. van der Linden MP, Feitsma AL, le Cessie S, Kern M, Olsson LM, Raychaudhuri S, Begovich AB, Chang M, Catanese JJ, Kurreeman FA, van Nies J, van der Heijde DM, Gregersen PK, Huizinga TW, Toes RE, van der Helm-Van Mil AH: Association of a single-nucleotide polymorphism in CD40 with the rate of joint destruction in rheumatoid arthritis. Arthritis Rheum 2009, 60:2242-2427.

5. Saibil SD, Jones RG, Deenick EK, Liadis N, Elford AR, Vainberg MG, Baerg H, Woodgett JR, Gerondakis S, Ohashi $P S$ : CD4+ and CD8+ $T$ cell survival is regulated differentially by protein kinase Ctheta, c-Rel, and protein kinase B. J Immunol 2007, 178:2932-2939.

6. Carmona L, Villaverde V, Hernández-García C, Ballina J, Gabriel R, Laffon A; EPISER Study Group: The prevalence of rheumatoid arthritis in the general population of Spain. Rheumatology (Oxford) 2002, 41:88-95.

7. Silman AJ, Ollier W, Holligan S, Birrell F, Adebajo A, Asuzu MC, Thomson W, Pepper L: Absence of rheumatoid arthritis in a rural Nigerian population. J Rheumatol 1993, 20:618-622.

8. Solomon L, Robin G, Valkenburg HA: Rheumatoid arthritis in an urban South African Negro population. Ann Rheum Dis 1975, 34:128-135.

9. Aho K, Heliovaara M: Risk factors for rheumatoid arthritis. Ann Med 2004, 36:242-251.

10. Pattison DJ, Symmons DP, Young A: Does diet have a role in the aetiology of rheumatoid arthritis? Proc Nutr Soc 2004, 63:137-143.

11. Kallberg H, Padyukov L, Plenge RM, Ronnelid J, Gregersen PK, van der Helm-van Mil AH, Toes RE, Huizinga TW, Klareskog L, Alfredsson L; Epidemiological Investigation of Rheumatoid Arthritis study group: Gene-gene and gene-environment interactions involving HLA-DRB1, PTPN22, and smoking in two subsets of rheumatoid arthritis. Am J Hum Genet 2007, 80:867-875.

12. Lee HS, Irigoyen $P$, Kern M, Lee A, Batliwalla F, Khalili H, Wolfe F, Lum RF, Massarotti E, Weisman M, Bombardier C, Karlson EW, Criswell LA, Vlietinck R, Gregersen PK: Interaction between smoking, the shared epitope, and anti-cyclic citrullinated peptide: a mixed picture in three large North American rheumatoid arthritis cohorts. Arthritis Rheum 2007, 56:1745-1753.

Published: 27 October 2009

doi:10.1186/gm98

(c) 2009 BioMed Central Ltd 